\title{
Interactive effects between physical forces and ecosystem engineers on seed burial: a case study using Spartina anglica
}

\author{
Zhenchang Zhu, Francesco Cozzoli, Nanyang Chu, Maria Salvador, Tom Ysebaert, \\ Liquan Zhang, Peter M. J. Herman and Tjeerd J. Bouma
}

Z. Zhu (zhenchang.zhu@nioz.nl), N. Chu, M. Salvador, T. Ysebaert, P. M. J. Herman and T. J. Bouma, Spatial Ecology Dept, Royal Netherlands Inst. for Sea Research (NIOZ), NL-4400 AC Yerseke, the Netherlands. MS also at: Univ. of Valencia, Av Blasco Ibanez 13, ES-46016 Valencia, Spain. TY also at: Inst. for Marine Resources and Ecosystem Studies (IMARES), Wageningen Univ., PB 77, NL-4401 NT Wageningen, the Netherlands. - F. Cozzoli, Dept of Biological and environmental Sciences and technologies, Univ. of Salento, IT-73100 Lecce, Italy. - L. Zhang, State Key Laboratory of Estuarine and Coastal Research, East China Normal Univ., CN-200062 Shanghai, PR China.

\begin{abstract}
Seed burial (i.e. vertical seed dispersal) has become increasingly valued for its relevance for seed fate and plant recruitment. While ecosystem engineers have been generally considered as the most important drivers of seed burial, the role of physical forces, such as wind or water flow, has been largely overlooked. Using tidal habitats as a model system, and a combination of flume and mesocosm experiments, we investigated the effects of 1) currents, 2) benthic animals with different engineering activities and 3) their interplay on seed burial of a common salt marsh pioneer plant, Spartina anglica. Our results reveal that in such systems, water flow can be of equal or higher importance than ecosystem engineers for seed burial. For passive seed-burying engineers (PSE), coupling their actions with currents produced synergistic seed burial effects, whereas the interactive effects were only additive for active seed-burying engineers (ASE). This paper extends current understanding of seed burial and seed bank formation by revealing the need to incorporate physical forces into seed burial mechanisms. We provide the first empirical evidence that physical forces influence seed burial by synergistically interacting with ecosystem engineers, thus highlighting the role of biophysical interactions as important drivers for vertical seed movement.
\end{abstract}

Seed dispersal is a critical process in the life history of flowering plants (Nathan and Muller-Landau 2000), often involving multiple steps (Vander Wall and Longland 2004). For many plant species, seeds undergo primary dispersal to the ground surface followed by secondary displacement to an alternate location, and seed burial may eventually deposit them into the soil seed bank (Chambers and Macmahon 1994). Compared with the distances covered by horizontal transport $(\mathrm{m} \sim \mathrm{km})$, seed burial is only a tiny step $(\mathrm{mm}$ $\sim \mathrm{cm}$ ) yet can have large consequences for seed fate, plant recruitment and vegetation dynamics.

In terrestrial ecosystems, seed burial has been shown to benefit seed survival by reducing exposure to biotic risks, e.g. predators or surface fungi (Chambers and Macmahon 1994, Gallery et al. 2007, Forey et al. 2011), and harsh physical conditions, e.g. fire, drought or frost (Cohen 1966, Forey et al. 2011). It could also improve seedling emergence by dispersing seeds to soil microsites favorable for germination (Hanzawa et al. 1988, Wenny 2001, Forey et al. 2011). More recently, seed burial has been demonstrated to be vital to seedling establishment of aquatic macrophytes, such as seagrasses and marsh plants. A layer of sediment on top of seeds shields them and emerging seedlings (Marion and Orth 2012, Zhu et al. 2014) from dislodgment by hydrodynamic forces and sediment erosion (Bouma et al. 2009, Balke et al. 2011, Infantes et al. 2011). In addition, seed burial is crucial for long-term population and community dynamics by fostering the formation of a persistent soil seed bank (Bakker et al. 1996, Thompson 1987). Despite the general recognition that seed burial is essential for a plant's reproductive success and long-term maintenance, there is insufficient knowledge on how seeds are moved into soil layers in natural ecosystems.

Although self-burial mechanisms exist for some species (Collins and Wein 1997), most plants rely on biotic or abiotic processes to incorporate their seeds into the soil seed bank (Chambers and Macmahon 1994). Biotic seed burial (i.e. vertical seed displacement by animal activity) has generally been considered the most universally relevant seed burial mechanism. Food-caching animals (e.g. ants, rodents and soil macro-invertebrates such as earthworms) have been well documented for their roles in seed burial of terrestrial plants (reviewed by Chambers and Macmahon 1994, Vander Wall and Longland 2004). In particular, mixing of soil layers (bioturbation, Meysman et al. 2006) by earthworms in their role as ecosystem engineers (i.e. organisms that modify their abiotic environments, Jones et al. 1994) has been considered to be the major driving force for seed burial and seed bank formation in various terrestrial ecosystems (Milcu et al. 2006, Eisenhauer and Scheu 2008, Forey et al. 2011). Much less is 
known about seed burial of aquatic plants in general. Similar to earthworms, several recent studies on seagrasses have shown that marine worm (polychaete) engineers are also able to bury seagrass seeds either directly via active transport or indirectly by sediment reworking (Valdemarsen et al. 2011, Delefosse and Kristensen 2012, Blackburn and Orth 2013).

In spite of the clear importance of physical forces (e.g. wind, water movement) in driving horizontal seed movement (Koch et al. 2010, Nathan et al. 2011) and their ubiquity in nature, their role in seed burial has been largely overlooked. There are only a few studies on the role that rainfall plays in promoting the entry of seeds into the terrestrial soil matrix (Benvenuti 2007, Marthews et al. 2008). Physical forces, interacting with ecosystem engineers, are known to drive soil/sediment dynamics (Meysman et al. 2006, Corenblit et al. 2011) and can be predicted to also affect seeds.

To improve our understanding of the factors and mechanisms underlying the seed burial processes, this paper examines the importance of physical forces and their interplay with ecosystem engineers for seed burial by using tidal flats as a model system. In such systems, seedling recruitment of marine macrophytes (e.g. pioneer marsh plants and seagrasses) mainly takes place in the pioneer zone on the higher tidal flats (Marion and Orth 2012, Zhu et al. 2014), where sediment dynamics (e.g. erosion and accretion) is governed by hydrodynamics and sediment transport, tightly coupled with the engineering activities of benthic animals (Herman et al. 1999, Widdows and Brinsley 2002). These characteristics make it a suitable model system to study seed burial resulting from biophysical coupling.

Using a combination of flume and mesocosm experiments, we specifically ask: 1) what the relative importance of physical forces versus ecosystem engineers is for seed burial in this intertidal ecosystem; 2) whether physical forces can affect seed burial through interacting with ecosystem engineers and how; and 3) whether interactive effects vary between species that differ in engineering modality.

\section{Material and methods}

\section{Target species}

To address these questions, we focus on a common salt marsh pioneer plant, Spartina anglica (Nehring and Hesse 2008). Recruitment of this plant starts with dispersal of seeds to adjacent tidal mudflats. Here, successful seedling establishment requires the burial of seeds into the sediment matrix (Zhu et al. 2014) inhabited by a diverse benthic infauna community (Snelgrove 1998, Herman et al. 1999). Four benthic species commonly found in northwest European tidal flats were employed in our manipulative experiments. Their engineering modalities grouped by feeding and burrowing behaviors are as follows:

1) The lugworm Arenicola marina is a deep-burrowing, subsurface, deposit-feeding polychaete. Arenicola marina is an upward conveyor of sediment that feeds headdown in J-shaped burrows. It has a strong capacity for particle reworking by ingesting sediment at depths in a feeding funnel and ejecting a characteristic 'worm-like' faecal casts at the surface (Kristensen 2001). This behavior enables $A$. marina to bury seagrass seeds to relatively great depths by covering the seeds with its massive depositions of faecal casts (Delefosse and Kristensen 2012).

2) The ragworm Alitta virens a.k.a. Nereis virens lives in semi-permanent U- or Y-shaped burrows in the sediment, which may develop into burrow galleries over time. Alitta virens behaves in almost the same way as its close relative, Hediste diversicolor (Kristensen 2001), which has been shown to actively locate and move seeds to shallow depths in their burrows (Delefosse and Kristensen 2012). Both species have been described as omnivores and detritivores that feed by swallowing surface sediments as well as plant and animal remains around the burrow opening (Kristensen 2001).

3) The cockle Cerastoderma edule is a motile, obligate suspension-feeding bivalve, which crawls through the top few $\mathrm{cm}$ of sediment (Kamermans 1994). The physical structure of its shell protruding from the sediment surface increases bottom roughness. Its crawling movements destabilize the sediment surface and, by opening and sudden adduction of the valves, $C$. edule causes sediment to become resuspended (Montserrat et al. 2009).

4) The Baltic clam Macoma balthica is a facultative surfacedeposit feeding bivalve (Kamermans 1994). In muddy sediments, $M$. balthica normally lives at shallow depths $(1-5 \mathrm{~cm})$. During surface-deposit feeding, the animal uses its flexible inhalant siphon to manipulate and ingest the surface sediment around the siphon shaft in a radial fashion, changing the properties of the bed. The grazing of $M$. balthica also disrupts sediment-stabilizing biofilm and increases susceptibility to erosion (Willows et al. 1998).

Generally, two types of seed burial were identified in our experiments. Alitta virens functioned as an active seed burying engineer (ASE), while M. balthica, C. edule and A. marina influenced seed burial mainly through seed entrapment and sediment mixing, and are, thus, viewed as passive seed burying engineers (PSE).

\section{Animal, seed and sediment preparation}

Individuals of $C$. edule, M. balthica and A. marina were collected from the tidal flats of the Oosterschelde and Westerschelde, the Netherlands. Alitta virens was acquired from a bait shop (<www.topsybaits.nl $>$ ), which facilitated collecting a large number of the desired body size. Before use, they were kept in aerated containers with sediment and filtered Oosterschelde water at a constant temperature of $18^{\circ} \mathrm{C}$ and fed with an Isochrysis galbana algal solution.

Spartina anglica seeds $(17.6 \pm 1.4 \mathrm{~mm}$ length, $2.0 \pm$ $0.1 \mathrm{~mm}$ width, Fig. 1a) were collected from salt marshes in the Westerschelde, the Netherlands, where the sediment $(45.0 \mu \mathrm{m}$ median grain size and $66.5 \%$ mud content) for experimental use was also collected from the top layer $(<5 \mathrm{~cm})$ of the mudflats. Prior to the experiments, the sediment was sieved through a $1-\mathrm{mm}$ mesh sieve to remove large particles, seeds and macrofauna, and to homogenize the sediments. Meiofauna remain in the sediment but have a negligible effect on sediment reworking (Willows 
et al. 1998). To minimize handling effect on sediment grain size, we sieved the sediments by manually pressing the sediments through the sieve, rather than washing it through with water, as the latter is likely to cause loss of fine sediments.

\section{Flume experiments}

\section{Annular flume}

To apply currents in our experiments, we used annular flumes (Fig. 1c), which are a variation of the design described by (Widdows et al. 1998). They consist of two concentric cylinders of transparent acrylic material, creating a $10 \mathrm{~cm}$ wide channel with a surface of ca $0.15 \mathrm{~m}^{2}$. Currents are created with a smooth, adjustable rotating disk, which is driven by a microprocessor-controlled engine. Prior to the
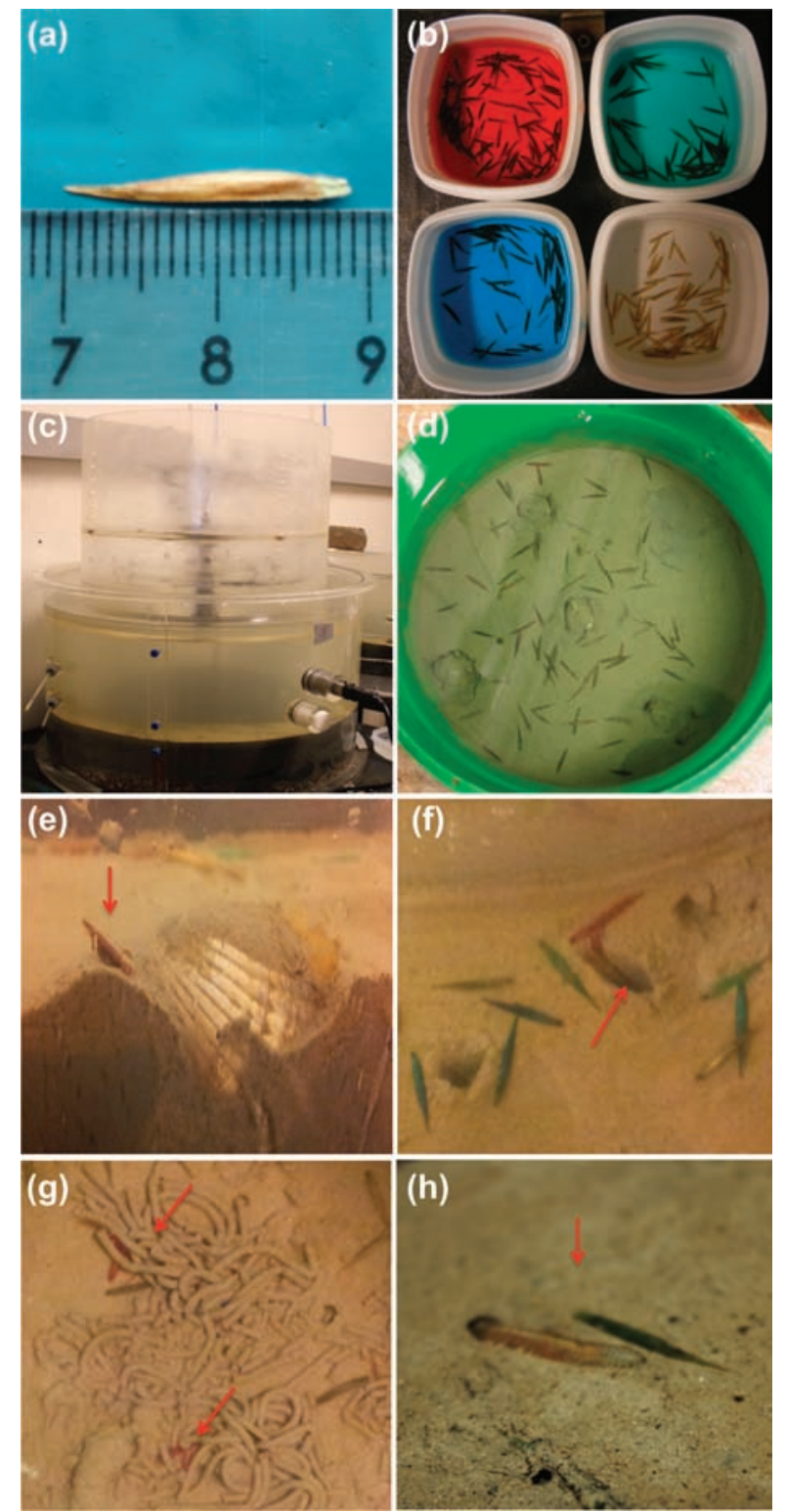

Figure 1. Spartina seed (a); Seeds of colour groups (b); Experiment units: annular flume (c) and bucket in the mesocosm (d); Seed entrapment by the protruding shell of $C$. edule (e), pits created by $M$. balthica (f), and fecal casts of $A$. marina (g); Active seed collecting behaviour of $A$. virens (h). experiments, the prepared sediment was put in a flume, mixed to a smooth mass and allowed to consolidate for three days. The flumes were then filled with 31.41 of filtered seawater.

\section{Treatments}

To investigate seed burial from purely physical processes, we applied a 'currents only' treatment (PHY) excluding animals. To study the interactive effects between physical force and ecosystem engineers, treatments combining both currents and animals (BIO $\times$ PHY) were applied separately on the different species. The effect of the animals in the absence of currents (BIO) was tested in mesocosm studies. To facilitate comparisons between species, we used an equivalent total biomass (ash free dry weight, AFDW, mg $\mathrm{m}^{-2}$, Table 1). Dividing by the number of individuals, we calculated the individual body size (AFDW in $\mathrm{mg}$ ) needed for each species, and this was then converted into body length with the conversion coefficients provided from the NIOZ - Yerseke Monitor Taskforce. For all these species, this total biomass is within the range found in the field (Ysebaert and Herman 2002). To examine if seed burial effect is related to the total biomass of the ecosystem engineer, we used two biomass treatments for $M$. balthica, the same total biomass value used for the other species and a low total biomass (Table 1).

For each treatment, two flumes (replicates) were used. For each species, similarly sized individuals were introduced into the flume and allowed time to burrow. The vast majority of the animals were found to bury themselves within a few minutes. Those that did not burrow were replaced with other individuals. After the animals had acclimated for two days, 200 waterlogged seeds of four color groups (Fig. $1 \mathrm{~b}, 50$ each of red, green, blue and uncolored seeds) were released into the water column and allowed to settle down to the sediment surface. Seeds were color-coated with food dye (bakery ingredient, <www.steensma.com $>$ ) to 1) enhance their visibility during observation, and 2) provide replicate measurements of seed burial.

\section{Protocol}

Each flume experiment lasted for 4.5 days. To simulate the two tidal cycles found in the intertidal mudflats, two runs of currents were applied each day from day 1 to 4 . Between these two runs, there were intervals of ca $3 \mathrm{~h}$ to ensure the settlement of suspended sediment. Only one run was carried out on day 5 when the experiment ended and, thereafter, seed burial data were collected. We did not simulate fluctuating tidal height as occurs in the field but adopted the typical current velocities observed in the pioneer zone of the marshes in the Scheldt estuary (Bouma et al. 2005), as the bed shear stress in the annular flume is determined by current velocity rather than water depth (Widdows et al. 1998, Willows et al. 1998). In each run, the current velocity was increased during the first step from 0 to $10 \mathrm{~cm} \mathrm{~s}^{-1}$ and subsequently in steps of $5 \mathrm{~cm} \mathrm{~s}^{-1}$ to a maximum velocity of $25 \mathrm{~cm} \mathrm{~s}^{-1}$. Each step lasted $20 \mathrm{~min}$. With increasing velocity, an increasing amount of sediment was eroded and re-suspended into the water column. The flume was oxygenated between the two runs. 
Table 1. Treatments of PHY (currents only), BIO (animals only) and BIO $\times$ PHY (coupling between animals and currents); parameters related with animals were given for each treatment, respectively.

\begin{tabular}{|c|c|c|c|c|c|c|}
\hline Treatments & & $\begin{array}{l}\text { Total biomass } \\
\text { (AFDW, mg) }\end{array}$ & No. of ind. & $\begin{array}{l}\text { Biomass density } \\
\left(\text { AFDW, } \mathrm{mg} \mathrm{m}^{-2}\right)\end{array}$ & $\begin{array}{l}\text { Ind. body } \\
\text { length }(\mathrm{cm})\end{array}$ & Abbr. \\
\hline $\mathrm{PHY}$ & - & - & - & - & - & $\mathrm{PHY}$ \\
\hline \multirow[t]{5}{*}{$\mathrm{BIO} \times \mathrm{PHY}$} & M. balthica & 583 & 24 & 38.9 & 1.4 & Mb $\times$ PHY_Low \\
\hline & M. balthica & 2428 & 100 & 161.9 & 1.4 & $\mathrm{Mb} \times \mathrm{PHY}$ \\
\hline & C. edule & 2428 & 24 & 161.9 & 3 & $\mathrm{Ce} \times \mathrm{PHY}$ \\
\hline & A. marina & 2428 & 24 & 161.9 & 6 & $\mathrm{Am} \times \mathrm{PHY}$ \\
\hline & A. virens & 2428 & 24 & 161.9 & 10 & $\mathrm{Av} \times \mathrm{PHY}$ \\
\hline \multirow[t]{4}{*}{$\mathrm{BIO}$} & M. balthica & 809 & 33 & 161.9 & 1.4 & $\mathrm{Mb}$ \\
\hline & C. edule & 809 & 8 & 161.9 & 3 & $\mathrm{Ce}$ \\
\hline & A. marina & 809 & 8 & 161.9 & 6 & $\mathrm{Am}$ \\
\hline & A. virens & 809 & 8 & 161.9 & 10 & $A v$ \\
\hline
\end{tabular}

\section{Data collection}

To quantify the sediment erosion caused by currents and their interactions with ecosystem engineers, water turbidity was measured using an optical backscatter sensor (OBS $3+$, Campbell scientific) every $30 \mathrm{~s}$ during each run. The OBS sensors were calibrated by gravimetric analysis, and the data were converted into suspended sediment concentration (SSC, $\mathrm{g}^{-1}$ ). Peak SSC served as a proxy to compare the capacity to rework sediment between treatments.

Seeds were regarded as buried when they were no longer visible from the surface. Unburied seeds were removed, classified according to their color and counted. Green and blue seeds were pooled together as one group, with the other two colors forming the second group, due to the difficulties in distinguishing blue and green seeds after processing. Total burial (\%) was measured as the number of buried seeds divided by the total number of deployed seeds. Forty sediment core samples were randomly taken by syringes (diameter $=3.6 \mathrm{~cm}$ ) to a depth of $10 \mathrm{~cm}$ and then sliced every $1 \mathrm{~cm}$ to determine the depth of seed burial. The depth of each seed was recorded as the upper limit of its recovery depth range. Thereafter, the proportion of seeds buried at each depth was estimated for each treatment.

\section{Mesocosm experiments}

To quantify seed burial effects of these four species under the 'no currents' condition (BIO), a mesocosm experiment was performed in plastic buckets (ca $0.05 \mathrm{~m}^{2}$ surface area, Fig. 1d) with comparable seed density (20 for each color group) and animal biomass to the flume experiments (Table 1). After compaction of the sediment (depth ca $15 \mathrm{~cm}$ ), each bucket was filled by filtered seawater to a water level of $10 \mathrm{~cm}$ and kept oxygenated. Animals and seeds were introduced in the same way as in the flume experiment.

Since very few seeds were buried in this experiment the top $1 \mathrm{~cm}$ sediment layer was carefully excavated using a spoon and sieved to detect the buried seeds. The buried seeds were all found within this top layer with most of them being nominally covered by a thin sediment layer, except for the treatment with $A$. virens. To acquire more accurate depths of seed burial by $A$. virens under the 'no currents' condition, a supplementary experiment was conducted by using five PVC tubes (diameter $=20 \mathrm{~cm}$, height $=20 \mathrm{~cm}$ ) to each of which 20 seeds and three worms were introduced. These cores were immersed (10 cm above core surface) in a tank with oxygenated filtered seawater. On day 5, the sediment cores were sliced every $1 \mathrm{~cm}$, by applying a piston pushed up from the bottom of the tube to extrude the sediment in $1-\mathrm{cm}$ increments. The slicing process terminated when all the buried seeds were retrieved from the sediment by rinsing the samples through a $1-\mathrm{mm}$ mesh sieve. The burial depths of the recovered seeds were recorded, and the proportion of seeds buried at each depth was calculated.

\section{Data analysis}

Pairwise t tests showed that seed color did not affect burial, since there was no significant difference of total seed burial among color groups $(\mathrm{p}=0.78)$. One-way ANOVAs were applied to examine whether total seed burial $(n=4,2$ color groups $\times 2$ flumes/buckets) varied 1) between BIO,

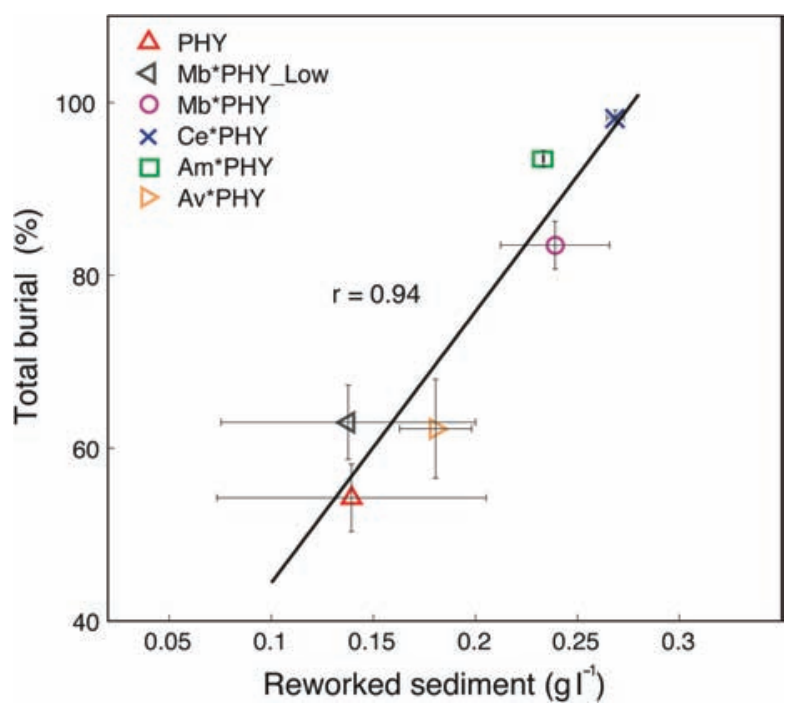

Figure 2. A linear correlation between total burial (Mean $\pm \mathrm{SE}$, $\mathrm{n}=4$ ) and the amount of reworked sediment (Peak SSC, Mean \pm $\mathrm{SE}, \mathrm{n}=2$ ) under purely physical process $(\mathrm{PHY})$ and the coupling between currents and animals (the rest). 
$\mathrm{PHY}$ and $\mathrm{BIO} \times \mathrm{PHY}$ treatments, and 2) between species in the $\mathrm{BIO}$ and $\mathrm{BIO} \times \mathrm{PHY}$ treatments, respectively. To test whether there were interactive effects between the currents and animals, one-way ANOVA was also employed to test the difference between total seed burial under $\mathrm{BIO} \times \mathrm{PHY}$ treatments with the sum of their separate effects i.e. BIO + PHY (adding the mean value of PHY to every single value of $\mathrm{BIO})$.

To detect whether seed burial depth differed between treatments, we used one-way ANOVA to compare the proportion of seeds buried at relatively shallow and deeper depths. Seed proportion in the depth range of $0-2 \mathrm{~cm}$ ( $\mathrm{n}=2$, except $\mathrm{n}=5$ for $A$. virens) was compared for all the treatments, whereas comparisons at the range of $>2 \mathrm{~cm}$ were done for those that resulted in seed burial deeper than $2 \mathrm{~cm}$.

Post hoc pairwise comparisons were achieved through Tukey HSD-tests. Prior to analysis, the data was arcsinetransformed to improve data normality. To examine whether seed burial quantity is linked with sediment reworking ability, a linear correlation was carried between total seed burial and peak SSC. All the statistical analyses were done in $\mathrm{R}(<$ www.R-project.org $>$ ), applying a significance level of $\alpha=0.05$.

Data available from the Dryad Digital Repository: $<$ http://dx.doi.org/10.5061/dryad.23j62 > (Zhu et al. 2015).

\section{Results}

\section{General observation}

In the flume experiments, seeds started moving once current velocity reached $10 \mathrm{~cm} \mathrm{~s}^{-1}$; while moving near the bottom, it was observed that some seeds were trapped by protruding shells of Cerastoderma edule (Fig. 1e) and depressions caused by Macoma balthica (Fig. 1f). This was not observed for these two species in the absence of currents. During both flume and mesocosm experiments, some seeds were seen covered by the faecal casts of Arenicola marina (Fig. 1g). Only Alitta virens was observed to deliberately seize and pull seeds into their burrows (Fig. 1h) regardless of the presence or absence of currents. When buried seeds were recovered, they were frequently found inside the burrows of $A$. virens.

\section{Total burial}

In the flume experiments, total seed burial showed a significant linear relationship $(p<0.01)$ with the amount of reworked sediment (Fig. 2). Less sediment was reworked by the active seed burial engineer (ASE) A. virens $(\mathrm{Av} \times \mathrm{PHY})$, which also buried much fewer seeds than the other species. The actions of the passive seed burial engineer (PSE) C. edule (Ce $\times \mathrm{PHY})$, however, resulted in the greatest total seed burial as well as the highest amount of eroded sediment.

Total seed burial significantly differed $(\mathrm{p}<0.001)$ between treatments (Fig. 3). For PHY treatment, 54.3 $\pm 3.9 \%$ (Mean $\pm \mathrm{SE}$ ) of the seeds were buried. This was much higher than that from any BIO treatment (Table 2), which was
$3.8 \pm 1.6 \%, 4.3 \pm 2.1 \%, \quad 13.1 \pm 2.1 \%$ and $16.3 \pm 2.2 \%$ for $M$. balthica (Mb), C. edule (Ce), A. marina (Am) and $A$. virens (Av), respectively. Among the $\mathrm{BIO}$ treatments, total burial was not different between the two worm species, $A$. marina and $A$. virens, whereas both of them resulted in higher total seed burial than the two bivalve species, M. balthica and C. edule (Table 2).

$\mathrm{BIO} \times \mathrm{PHY}$ treatments resulted in significantly higher total seed burial (Table 2) than for the PHY treatment, except for ASE $A$. virens (Av $\times$ PHY) and low density $M$. balthica $(\mathrm{Mb} \times \mathrm{PHY}$ Low). For $M$. balthica, a higher density of individuals $(\mathrm{Mb} \times \mathrm{PHY})$ generated significantly higher total seed burial (Table 2). For all PSEs, their joint action with currents produced significant interactive effects so that $\mathrm{BIO} \times \mathrm{PHY}$ treatments with PSEs lead to greater total seed burial than the sum of BIO and PHY treatments, whereas there was no significant difference for ASE $A$. virens in this respect (Table 2).

\section{Seed burial depth}

There was a general trend of decreasing seed proportion with burial depth, and for all the treatments, more than two thirds of the buried seeds were found at relatively shallow depths (0-2 cm, Fig. 4).

Seed burial depth varied between treatments (Fig. 4). Seeds were only buried to shallower depths $(86.4 \%$ at $1 \mathrm{~cm}$ and $13.6 \%$ at $2 \mathrm{~cm}$ ) by the purely physical process (PHY). The range of burial depth became, however, much broader with some seeds buried more deeply when coupled with animals. For all the $\mathrm{BIO} \times \mathrm{PHY}$ treatments, the maximum recovery depth reached $6 \mathrm{~cm}$, except for the one of low density of $M$. balthica (MbXPHY_Low) with a maximum depth of $4 \mathrm{~cm}$. Without currents, seed burial was very limited for all PSEs (Mb, Ce and Am). The recovered seeds were only within the top $1 \mathrm{~cm}$, most of which were found only nominally covered by a thin layer of sediment.

In contrast, ASE $A$. virens (Av) still buried seeds over a broad range covering $0-5 \mathrm{~cm}$ in the absence of currents (Fig. 4). Joint action with currents (Av $\times$ PHY) did not reinforce seed burial effect, either at deeper or shallower depths, compared to their separate effects. There was no significant difference $(p=0.626)$ in the proportion of seeds buried deeper than $2 \mathrm{~cm}$ between $\mathrm{Av}$ and $\mathrm{Av} \times \mathrm{PHY}$ nor was there a significant difference $(p=0.456)$ between $A v \times$ PHY and PHY in the proportion of seeds buried at shallower depths $(0-2 \mathrm{~cm})$.

\section{Discussion}

Traditionally, ecosystem engineers have been credited as the being the most important drivers for seed burial in both terrestrial and aquatic plants (Chambers and Macmahon 1994, Blackburn and Orth 2013). Using a tidal marsh as a model system, our study reveals that 1) physical force can be at least as important as the effect of ecosystem engineers for seed burial, and 2) there are interactive effects between these two agents, serving as an important seed burial driver. Our flume experiments show that purely physical force (i.e. currents) can lead to seed burial. However, physical force 
Table 2. Statistical results for pairwise comparisons (TukeyHSD-test) of total burial between treatments; Definitions for all the abbreviations of treatments are given in Table 1; ' $\mathrm{BIO}+\mathrm{PHY}^{\prime}$ refers to the cumulative total burial of $\mathrm{BIO}(\mathrm{Mb}, \mathrm{Ce}, \mathrm{Am}$ or $\mathrm{Nv})$ and $\mathrm{PHY}$ treatments.

\begin{tabular}{|c|c|}
\hline Comparisons & $\mathrm{p}$ \\
\hline \multicolumn{2}{|l|}{$\mathrm{PHY}$ vs $\mathrm{BIO} \times \mathrm{PHY}$} \\
\hline PHY vs Mb×PHY_Low & 0.701 \\
\hline $\mathrm{PHY}$ vs $\mathrm{Mb} \times \mathrm{PHY}$ & $<0.001^{* * *}$ \\
\hline $\mathrm{PHY}$ vs CeXPHY & $<0.001^{* * *}$ \\
\hline $\mathrm{PHY}$ vs $\mathrm{Am} \times \mathrm{PHY}$ & $<0.001^{* * *}$ \\
\hline $\mathrm{PHY}$ vs Av $\times \mathrm{PHY}$ & 0.756 \\
\hline \multicolumn{2}{|l|}{$\mathrm{PHY}$ vs $\mathrm{BIO}$} \\
\hline PHY vs Mb & $<0.001^{* * *}$ \\
\hline PHY vs Ce & $<0.001^{* * *}$ \\
\hline PHY vs Am & $<0.001^{* * *}$ \\
\hline PHY vs Av & $<0.001^{* * *}$ \\
\hline \multicolumn{2}{|l|}{$\mathrm{BIO} \times \mathrm{PHY}$ vs $\mathrm{BIO}$} \\
\hline $\mathrm{Mb} \times \mathrm{PHY}$ vs $\mathrm{Mb}$ & $<0.001^{* * *}$ \\
\hline $\mathrm{Ce} \times \mathrm{PHY}$ vs $\mathrm{Ce}$ & $<0.001^{* * *}$ \\
\hline $\mathrm{Am} \times \mathrm{PHY}$ vs Am & $<0.001^{* * *}$ \\
\hline $\mathrm{Av} \times \mathrm{PHY}$ vs Av & $<0.001^{* * *}$ \\
\hline \multicolumn{2}{|l|}{$\mathrm{BIO} \times \mathrm{PHY}$ vs $\mathrm{BIO}+\mathrm{PHY}$} \\
\hline $\mathrm{Mb} \times \mathrm{PHY}$ vs Mb $+\mathrm{PHY}$ & $<0.001^{* * *}$ \\
\hline $\mathrm{Ce} \times \mathrm{PHY}$ vs $\mathrm{Ce}+\mathrm{PHY}$ & $<0.001^{* * *}$ \\
\hline $\mathrm{Am} \times \mathrm{PHY}$ vs Am $+\mathrm{PHY}$ & $<0.001^{* * *}$ \\
\hline $\mathrm{Av} \times \mathrm{PHY} v s \mathrm{Av}+\mathrm{PHY}$ & 0.762 \\
\hline \multicolumn{2}{|l|}{ High vs low density } \\
\hline Mb $\times$ PHY vs Mb $\times$ PHY_Low & $0.008^{* *}$ \\
\hline \multicolumn{2}{|l|}{ Between species $(\mathrm{BIO} \times \mathrm{PHY})$} \\
\hline $\mathrm{Mb} \times \mathrm{PHY}$ vs $\mathrm{Ce} \times \mathrm{PHY}$ & $<0.001^{* * *}$ \\
\hline $\mathrm{Mb} \times \mathrm{PHY}$ vs $\mathrm{Am} \times \mathrm{PHY}$ & 0.13 \\
\hline $\mathrm{Mb} \times \mathrm{PHY}$ vs $\mathrm{Av} \times \mathrm{PHY}$ & $0.006^{* *}$ \\
\hline $\mathrm{Ce} \times \mathrm{PHY}$ vs $\mathrm{Am} \times \mathrm{PHY}$ & 0.094 \\
\hline $\mathrm{Ce} \times \mathrm{PHY}$ vs $\mathrm{Av} \times \mathrm{PHY}$ & $<0.001^{* * *}$ \\
\hline $\mathrm{Am} \times \mathrm{PHY}$ vs $\mathrm{Av} \times \mathrm{PHY}$ & $<0.001^{* * *}$ \\
\hline \multicolumn{2}{|l|}{ Between species (BIO) } \\
\hline $\mathrm{Mb}$ vs $\mathrm{Ce}$ & 0.996 \\
\hline $\mathrm{Mb}$ vs Am & $0.029^{*}$ \\
\hline $\mathrm{Mb}$ vs Av & $0.004^{* *}$ \\
\hline Ce vs Am & $0.043^{*}$ \\
\hline Ce vs Av & $0.006^{* *}$ \\
\hline Am vs Av & 0.698 \\
\hline
\end{tabular}

Significance level: ${ }^{* *} 0.001,{ }^{* *} 0.01,{ }^{*} 0.05$.

and ecosystem engineers can act synergistically, resulting in a greater quantity of buried seeds at deeper burial depths.

\section{Biophysical seed burial: towards a general concept}

Our results indicate that the outcome of seed burial by the coupling of biophysical agents was dependent on the functional properties of the ecosystem engineers. The coupling of currents and the active seed burial engineer (ASE) Alitta virens only resulted in additive seed burial effects. This could be due to the low sediment reworking capacity of $A$. virens and the nature of active seed displacement that operates independently of physical forces. Without currents, this species can still bury seeds through direct seed transport to their burrows. This active seed burying behaviour is analogous to other marine worms Hediste diversicolor and Neanthes succinea (Delefosse and Kristensen 2012, Blackburn and

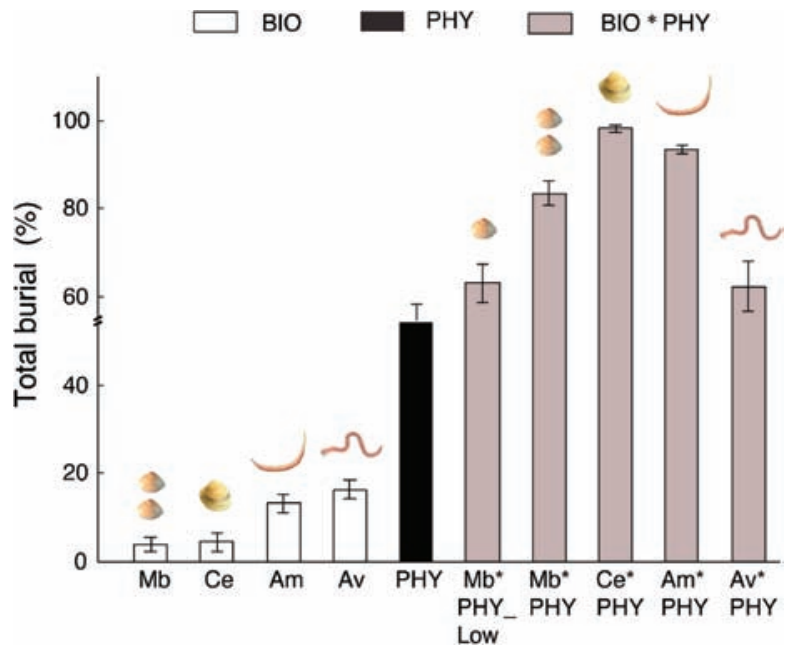

Figure 3. Proportions of seeds (Mean $\pm S E, n=4$ ) that were buried for all the treatments of BIO (animals only), PHY (currents only) and $\mathrm{BIO} * \mathrm{PHY}$ (coupling between animals and currents).

Orth 2013) and also earthworm Lumbricus terrestris (Milcu et al. 2006, Regnier et al. 2008). In contrast, passive seed burial engineers (PSE) and currents interactively produced large, synergistic effects that enhanced both total burial and seed burial depth, regardless of the different modalities of their bioturbation activities (Fig. 3).

Two mechanisms can be involved in such biophysical synergy (Fig. 5). 1) Enhancement of seed entrapment. In our study, some seeds were trapped by biogenic microtopography (e.g. protruding shells, depressions and faecal casts, Fig. 1) while moving along the sediment surface with currents. An earlier flume study showed that the presence of the polychaete Clymenella torquata greatly enhanced seed entrapment of seagrass seeds (Luckenbach and Orth 1999). Once seeds are trapped within burrows or depressions, they might be further displaced downward by animal movement or covered by infilling sediment, resulting in deep burial. 2) Promotion of sediment mixing. Through destabilizing the substrate, ecosystem engineers promote erosion and spatial redistribution of sediments (Widdows and Brinsley 2002, Montserrat et al. 2008, Kristensen et al. 2013, this study). They can also aid sediment mixing via bio-deposition, such as depositing particles as (pseudo) faeces, or bio-resuspension, such as ejecting liquefied faecal pellets into the water column (Graf and Rosenberg 1997, Meysman et al. 2006). The eroded and resuspended sediments may later be deposited and accumulate on top of seeds retained after settlement or entrapment.

The quantity of seeds buried by biophysical processes was found to differ between species due to species-specific variability on sediment reworking ability (Fig. 2). The strength of such effects was also linked to biotic parameters like population density, which was seen in our experiments with two different densities of Macoma balthica. Although not tested in the present study, it is likely that this also applies to other PSEs, since both sediment reworking (Willows et al. 1998) and seed retention (Luckenbach and Orth 1999) have been found to be related to species abundance. A study (Delefosse and Kristensen 2012) on the purely biological seed-burial effects of marine worms showed 


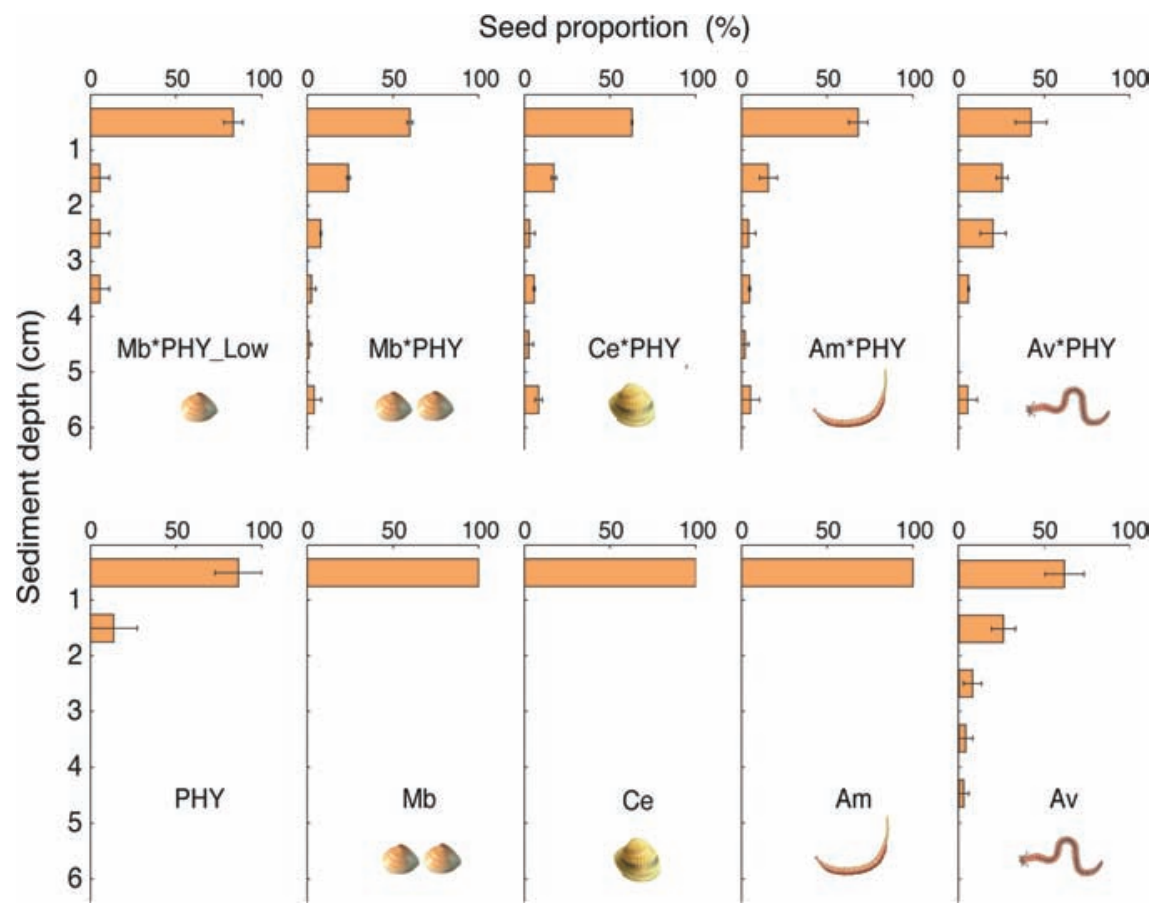

Figure 4. The vertical distribution of the buried seeds (Mean \pm SE, $n=2$, except $n=5$ for Av) for each treatment, respectively.

that seed burial quantity increased with animal abundance for PSEs, whereas the proportion of buried seeds was independent of individual density for the ASE $H$. diversicolor due to its selective and active search for seeds. Body size may
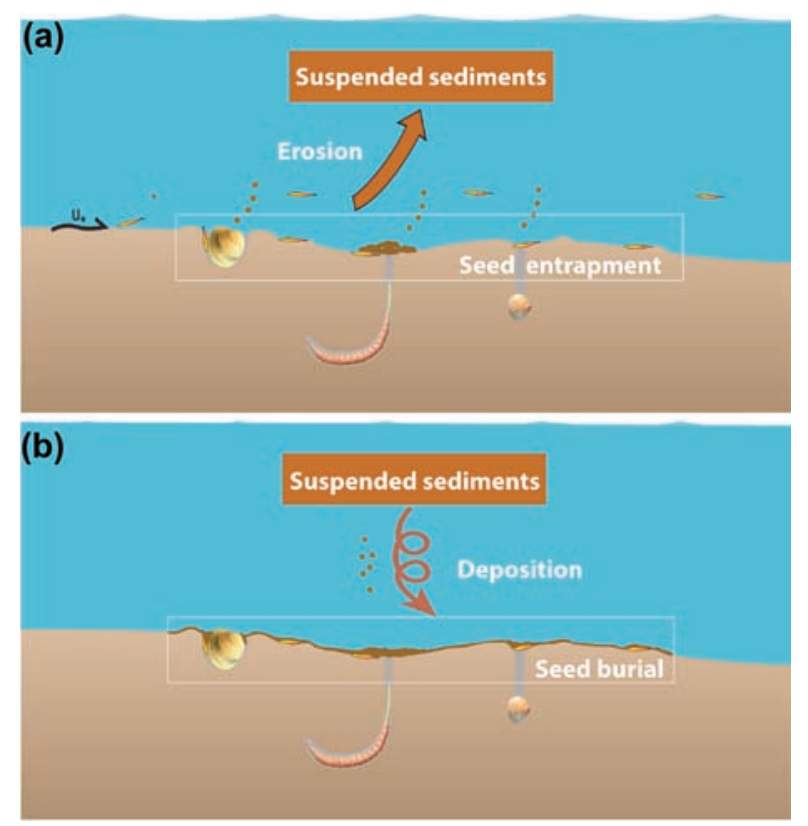

Figure 5. (a) Bottom roughness induced by PSEs ( $C$. edule, $A$. Marina and M. balthica; left to right) promotes the entrapment of seeds (in yellow) moving along or settling to the sediment surface. Co-currently, the coupling between currents and bioturbation by PSEs reinforces erosion and resuspension of sediment particles (brown dots). (b) The increased sediment availability in the water column serves as a source for subsequent sediment deposition facilitating the burial of the entrapped seeds. also be important for seed burial since it influences organism metabolism rate (Kleiber 1932), which serves as the fueling process for their engineering activities (Brown et al. 2004).

It must also be noted that seed burial rates estimated in our flume and mesocosm experiments should be treated with caution when extrapolated to the real world since we did not include all the parameters, such as waves, that may affect seed/sediment transport in the field. Nevertheless, these simplified but highly controlled laboratory experiments were effective to gain a mechanistic insight into the interactive effects between physical forces and different types of ecosystem engineers on seed burial.

\section{Relevance beyond intertidal systems}

Biophysical seed burial is likely to be applicable to various ecosystems. For instance, we can think about macrophytes growing in aquatic systems with flowing water, such as in estuaries, coasts, riverbanks and streamsides. Seed burial effect can be habitat-specific due to the differences in physical settings, such as the magnitude, frequency and duration of the physical force (i.e. water flow), and soil or sediment type. These variables not only determine the distribution of the benthic fauna (Cozzoli et al. 2013) but also primarily control the soil or sediment erosion processes that are amplified by the activities of ecosystem engineers (Widdows and Brinsley 2002, Meysman et al. 2006, Corenblit et al. 2011). Seed burial effects may also differ between plants in response to variable seed properties and specific interactions with their environment. For instance, seed morphology (e.g. length, width and eccentricity) and seed mass affected seed entrapment in soils (Chambers et al. 1991). Seed buoyancy can affect seed retention by entrapment structures in salt marshes (Chang et al. 2008). In addition, disturbance 
incidents, such as waves or raindrops, might also affect seed burial due to their capacity to induce vertical movement of seeds and soil/sediment particles (Chang et al. 2008, Marthews et al. 2008).

Previous studies have mainly focused on the importance of physical force in horizontal seed movement, e.g. the role of tidal currents and waves in driving the dispersal of seagrass seeds (Koch et al. 2010). Nonetheless, our study shows that the same physical force (i.e. currents) can drive both lateral seed transport (dispersal) and vertical translocation (retention). The former increases the probability of encountering a microsite that favors seed entrapment. By interacting with ecosystem engineers, physical force facilitates the remobilization of the particles, which can in turn lead to seed burial. In a sense, movement can result in better placement for retention.

The importance of physical force for seed burial is not restricted to aquatic systems. In terrestrial systems, wind or precipitation induced overland flow can move seeds over the soil surface to microsites (e.g. burrows, mounds) built by ecosystem engineers (Corenblit et al. 2011), and/or geophysical processes e.g. desiccation cracks (Burmeier et al. 2010). A wind tunnel experiment showed that seeds move frequently on smooth surfaces but were trapped on rougher surfaces (Johnson and Fryer 1992). On litter-covered surfaces, abiotic forces deposited seeds in the same locations as plant litter, after which animals often buried seeds in litter or under litter-covered surfaces (Chambers and Macmahon 1994). The potential couplings between physical forces such as wind or rainfall and terrestrial ecosystem engineers (e.g. ants, earthworms) on redistributing seeds and shaping soil dynamics, as well as their consequences for seed burial and soil seed bank formation, would be interesting topics for future studies.

\section{Conclusions}

Overall, this study contributes to a better mechanistic understanding of seed burial and seed bank formation by highlighting the need to incorporate physical forces into the mechanisms that drive seed entry into the soil or sediment. We present the first empirical evidence, to our knowledge, that physical force can significantly affect seed burial by synergistically interacting with ecosystem engineers, which underscores the significance of biophysical interactions as drivers for vertical seed movement. Although this present work was illustrated using intertidal ecosystems, similar mechanisms may be expected to operate in other aquatic and also non-aquatic ecosystems. Thus, an important challenge for the future will be to evaluate these mechanisms across ecosystem types.

Acknowledgements - We thank Jos van Soelen, Lennart van IJzerloo, Jeroen van Dalen, Hui Cheng, Tao Hong and Qin Zhu for field assistance, and thank THESUES project (FP7.2009-1, Contract 244104) and China Scholarship Council for funding.

\section{References}

Bakker, J. P. et al. 1996. Seed banks and seed dispersal: important topics in restoration ecology. - Acta Bot. Neerl. 45: 461-490.
Balke, T. et al. 2011. Windows of opportunity: thresholds to mangrove seedling establishment on tidal flats. - Mar. Ecol. Prog. Ser. 440: 1-9.

Benvenuti, S. 2007. Natural weed seed burial: effect of soil texture, rain and seed characteristics. - Seed Sci. Res. 17: 211-219.

Blackburn, N. J. and Orth, R. J. 2013. Seed burial in eelgrass Zostera marina: the role of infauna. - Mar. Ecol. Prog. Ser. 474: $135-145$.

Bouma, T. J. et al. 2005. Flow hydrodynamics on a mudflat and in salt marsh vegetation: identif-ying general relationships for habitat characterisations. - Hydrobiologia 540: 259-274.

Bouma, T. J. et al. 2009. Effects of shoot stiffness, shoot size and current velocity on scouring sediment from around seedlings and propagules. - Mar. Ecol. Prog. Ser. 388: 293-297.

Brown, J. H. et al. 2004. Toward a metabolic theory of ecology. - Ecology 85: 1771-1789.

Burmeier, S. et al. 2010. Desiccation cracks act as natural seed traps in flood-meadow systems. - Plant Soil 333: 351-364.

Chambers, J. C. and Macmahon, J. A. 1994. A day in the life of a seed - movements and fates of seeds and their implications for natural and managed systems. - Annu. Rev. Ecol. Syst. 25: 263-292.

Chambers, J. C. et al. 1991. Seed entrapment in alpine ecosystems - effects of soil particle-size and diaspore morphology. - Ecology 72: 1668-1677.

Chang, E. R. et al. 2008. To move or not to move: determinants of seed retention in a tidal marsh. - Funct. Ecol. 22: 720-727.

Cohen, D. 1966. Optimizing reproduction in a randomly varying environment. - J. Theor. Biol. 12: 119-129.

Collins, B. S. and Wein, G. R. 1997. Mass allocation and self-burial of Aristida tuberculosa florets. - J. Torrey Bot. Soc. 124: 306-311.

Corenblit, D. et al. 2011. Feedbacks between geomorphology and biota controlling Earth surface processes and landforms: a review of foundation concepts and current understandings. - Earth-Sci. Rev. 106: 307-331.

Cozzoli, F. et al. 2013. Application of non-linear quantile regression to macrozoobenthic species distribution modelling: comparing two contrasting basins. - Mar. Ecol. Prog. Ser. 475: 119-133.

Delefosse, M. and Kristensen, E. 2012. Burial of Zostera marina seeds in sediment inhabited by three polychaetes: laboratory and field studies. - J. Sea Res. 71: 41-49.

Eisenhauer, N. and Scheu, S. 2008. Invasibility of experimental grassland communities: the role of earthworms, plant functional group identity and seed size. - Oikos 117: 1026-1036.

Forey, E. et al. 2011. Importance of earthworm-seed interactions for the composition and structure of plant communities: a review. - Acta Oecol. 37: 594-603.

Gallery, R. E. et al. 2007. Diversity, host affinity, and distribution of seed-infecting fungi: a case study with Cecropia. - Ecology 88: 582-588.

Graf, G. and Rosenberg, R. 1997. Bioresuspension and biodeposition: a review. - J. Mar. Syst. 11: 269-278.

Hanzawa, F. M. et al. 1988. Directed dispersal - demographicanalysis of an ant-seed mutualism. - Am. Nat. 131: 1-13.

Herman, P. et al. 1999. Ecology of estuarine macrobenthos. - Adv. Ecol. Res. 29: 195-240.

Infantes, E. et al. 2011. Posidonia oceanica and Cymodocea nodosa seedling tolerance to wave exposure. - Limnol. Oceanogr. 56: 2223-2232.

Johnson, E. A. and Fryer, G. I. 1992. Physical characterization of seed microsites - movement on the ground. - J. Ecol. 80: 823-836.

Jones, C. G. et al. 1994. Organisms as ecosystem engineers. - Oikos 69: 373-386.

Kamermans, P. 1994. Similarity in food source and timing of feeding in deposit-feeding and suspension-feeding bivalves. - Mar. Ecol. Prog. Ser. 104: 63-75. 
Kleiber, M. 1932. Body size and metabolism. - Hilgardia 6: 315-353.

Koch, E. W. et al. 2010. The role of currents and waves in the dispersal of submersed angiosperm seeds and seedlings. - Restor. Ecol. 18: 584-595.

Kristensen, E. 2001. Impact of polychaetes (Nereis spp. and Arenicola marina) on carbon biogeochemistry in coastal marine sediments. - Geochem. Trans. 2: 92-103.

Kristensen, E. et al. 2013. Influence of benthic macroinvertebrates on the erodability of estuarine cohesive sediments: densityand biomass-specific responses. - Estuarine Coastal Shelf Sci. 134: 80-87.

Luckenbach, M. W. and Orth, R. J. 1999. Effects of a depositfeeding invertebrate on the entrapment of Zostera marina L. seeds. - Aquat. Bot. 62: 235-247.

Marion, S. R. and Orth, R. J. 2012. Seedling establishment in eelgrass: seed burial effects on winter losses of developing seedlings. - Mar. Ecol. Prog. Ser. 448: 197-207.

Marthews, T. R. et al. 2008. Burial and secondary dispersal of small seeds in a tropical forest. - J. Trop. Ecol. 24: 595-605.

Meysman, F. J. R. et al. 2006. Bioturbation: a fresh look at Darwin's last idea. - Trends Ecol. Evol. 21: 688-695.

Milcu, A. et al. 2006. Earthworms (Lumbricus terrestris) affect plant seedling recruitment and microhabitat heterogeneity. - Funct. Ecol. 20: 261-268.

Montserrat, F. et al. 2008. Benthic community-mediated sediment dynamics. - Mar. Ecol. Progr. Ser. 372: 43-59.

Montserrat, F. et al. 2009. Sediment segregation by biodiffusing bivalves. - Estuarine Coastal Shelf Sci. 83: 379-391.

Nathan, R. et al. 2011. Mechanistic models of seed dispersal by wind. - Theor. Ecol. 4: 113-132.

Nathan, R. and Muller-Landau, H. C. 2000. Spatial patterns of seed dispersal, their determinants and consequences for recruitment. - Trends Ecol. Evol. 15: 278-285.

Nehring, S. and Hesse, K.-J. 2008. Invasive alien plants in marine protected areas: the Spartina anglica affair in the European Wadden Sea. - Biol. Invas. 10: 937-950.
Regnier, E. et al. 2008. Impact of an exotic earthworm on seed dispersal of an indigenous US weed. - J. Appl. Ecol. 45: 1621-1629.

Snelgrove, P. R. 1998. The biodiversity of macrofaunal organisms in marine sediments. - Biodivers. Conserv. 7: 1123-1132.

Thompson, K. 1987. Seeds and seed banks. - New Phytol. 106: 23-34.

Valdemarsen, T. et al. 2011. Burial of seeds and seedlings by the lugworm Arenicola marina hampers eelgrass (Zostera marina) recovery. - J. Exp. Mar. Biol. Ecol. 410: 45-52.

Vander Wall, S. B. and Longland, W. S. 2004. Diplochory: are two seed dispersers better than one? - Trends Ecol. Evol. 19: $155-161$.

Wenny, D. G. 2001. Advantages of seed dispersal: a re-evaluation of directed dispersal. - Evol. Ecol. Res. 3: 51-74.

Widdows, J. and Brinsley, M. 2002. Impact of biotic and abiotic processes on sediment dynamics and the consequences to the structure and functioning of the intertidal zone. - J. Sea Res. 48: 143-156.

Widdows, J. et al. 1998. A benthic annular flume for in situ measurement of suspension feeding/biodeposition rates and erosion potential of intertidal cohesive sediments. - Estuarine Coastal Shelf Sci. 46: 27-38.

Willows, R. I. et al. 1998. Influence of an infaunal bivalve on the erosion of an intertidal cohesive sediment: a flume and modeling study. - Limnol. Oceanogr. 43: 1332-1343.

Ysebaert, T. and Herman, P. M. J. 2002. Spatial and temporal variation in benthic macrofauna and relationships with environmental variables in an estuarine, intertidal soft-sediment environment. - Mar. Ecol. Prog. Ser. 244: 105-124.

Zhu, Z. et al. 2014. Seed arrival and persistence at the tidal mudflat: identifying key processes for pioneer seedling establishment in salt marshes. - Mar. Ecol. Prog. Ser. 513: 97-109.

Zhu, Z. et al. 2015. Data from: Interactive effects between physical forces and ecosystem engineers on seed burial: a case study using Spartina anglica. - Dryad Digital Repository, $<$ http://dx.doi.org/10.5061/dryad.23j62 >. 